\title{
PERANCANGAN STRATEGI DIGITAL MARKETING COMMUNICATION BAGI INDUSTRI PERHOTELAN DALAM MENJAWAB TANTANGAN ERA POSMODEREN
}

\section{Design of Digital Marketing Communication Strategy for the Hospitality Industry to Answer the Postmodern Era Challenges}

\author{
${ }^{1)}$ Monika Teguh, ${ }^{2}$ Selvy Tri Ciawati \\ 1) 2)Program Studi Ilmu Komunikasi/Universitas Ciputra Surabaya \\ CitraLand CBD Boulevard 60219 - Surabaya
}

Diterima 05 Desember 2019/ Disetujui 07 Maret 2020

\begin{abstract}
The development of consumer culture in the era of technology has a direct impact on business competition in the hospitality sector. To be in a superior position in winning the competition, it requires the implementation of strategic planning. With the significant growth of internet users, the hotel industry must make good use of the situation, namely promoting digital marketing communication strategies. The purpose of this research is to design a digital marketing communication strategy for the Golden Tulip Legacy Hotel in Surabaya to overcome the postmodern era challenges. The research method is descriptive qualitative. The study is focused on the website and Instagram design, because it is the main access to information distribution of the Golden Tulip Legacy Surabaya. The informants in this study are selected speakers based on criteria that fit the purpose of the study. The method of data collection is done by observation, interviews, and documentation. The results of this study are the design of innovative digital marketing communication strategies that can be made with a management calendar, content formulation system, updated website features, optimized Instagram, and following the latest trends.
\end{abstract}

Keywords; marketing strategy, digital marketing communication, website, Instagram

\begin{abstract}
ABSTRAK
Perkembangan budaya konsumen di era teknologi berdampak langsung pada persaingan bisnis di dalam bidang perhotelan. Untuk berada di posisi yang unggul dalam memenangkan persaingan, diperlukan adanya implementasi dari perencanaan yang strategis. Dengan pertumbuhan pengguna internet yang signifikan, industri hotel harus memanfaatkan keadaan dengan baik, yakni melakukan promosi dengan strategi digital marketing communication. Tujuan dari penelitian ini adalah untuk merancang strategi digital marketing communication bagi Hotel Golden Tulip Legacy Surabaya agar dapat menjawab tantangan pada era postmodern. Jenis penelitian yang digunakan adalah kualitatif deskriptif yang berfokus pada website dan Instagram karena merupakan akses penyaluran informasi utama Golden Tulip Legacy Surabaya. Informan dalam penelitian ini adalah narasumber yang terpilih berdasarkan kriteria yang sesuai dengan tujuan penelitian. Metode pengumpulan data dilakukan dengan observasi, wawancara, dan dokumentasi. Hasil penelitian ini adalah perancangan strategi digital marketing communication yang inovatif dapat dibuat dengan kalender pengelolaan, sistem perumusan konten, pembaharuan fitur website, pengoptimalan Instagram, dan mengikuti tren terkini.
\end{abstract}

Kata kunci; strategi pemasaran, komunikasi pemasaran digital, website, Instagram

*Korespondensi Penulis:

monika.teguh@ciputra.ac.id 


\section{PENDAHULUAN}

Di era postmodern saat ini, terjadi berbagai perubahan dalam kehidupan masyarakat yang mempengaruhi dunia industri. Sebagai contoh terjadi peningkatan dalam hal pelayanan di bidang ekonomi, peranan media massa yang makin menguat, ketergantungan ekonomi dunia yang semakin meningkat, dan perubahan pada pola konsumsi masyarakat (Ilham, 2018). Hal ini juga berdampak pada industri pariwisata dalam bidang perhotelan. Badan Pusat Statistik Provinsi Jawa Timur menyatakan bahwa Kota Surabaya merupakan kota yang memiliki jumlah hotel bintang terbanyak dengan jumlah 97 hotel bintang dibandingkan dengan kota lain yang berada di Jawa Timur. Dengan banyaknya hotel bintang di Surabaya, tentunya menjadikan adanya persaingan yang ketat untuk mendapatkan pelanggan yang akan menikmati fasilitas terbaik sebagai keunggulan dari hotel. Untuk berada di posisi yang unggul dalam memenangkan persaingan di industri perhotelan, diperlukan adanya pemikiran dan implementasi dari perencanaan yang strategis supaya perusahaan dapat bertahan dalam persaingan bisnis. Inovasi pada bisnis merupakan hal efektif yang menjadikan perusahaan sukses dengan pendekatan inovasi yang berbeda dalam mendorong penciptaan sebuah nilai dan daya saing (Ikeda \& Marshall, 2016).

Dalam mengembangkan inovasi bisnis baru diperlukan pemahaman akan pelanggan, manfaat yang diberikan perusahaan kepada pelanggan, dan keuntungan yang diperoleh dari inovasi tersebut (Hargadon, 2015). Inovasi bisnis menjadi salah satu strategi yang dapat digunakan perusahaan untuk memperkuat posisi perusahaan dalam pasar. Hal ini juga berlaku pada negara kita Indonesia, di mana percepatan inovasi juga berperan penting sebagai salah satu strategi kunci untuk memperkuat posisi negara Indonesia dalam persaingan bisnis di Asia Tenggara seperti yang dapat dilihat bahwa proyeksi pertumbuhan ekonomi dengan percepatan inovasi akan meningkat dari tahun ke tahun. Untuk mempersiapkan keadaan yang semakin selektif dalam menghadapi proyeksi ekonomi, maka perusahaan tidak boleh melupakan budaya konsumen yang berkembang saat ini. Perusahaan harus meyadari bahwa di era teknologi seperti saat ini, terjadi pergeseran budaya konsumen. Konsumen tidak lagi hanya mencari informasi melalui media konvensional, namun sudah ada peralihan ke media digital. Sebuah studi yang dilakukan di kota Depok menunjukkan bahwa saluran komunikasi digital seperti chatting mampu menunjang kegiatan bisnis. Pengusaha yang mampu menggunakan saluran komunikasi digital dengan tepat bisa memperoleh dan menyebarkan informasi lebih cepat (Anggraeni et al., 2019). Demikian juga bagi brand yang berhasil mengelola komunitas online nya dengan baik, memiliki tingkat kesuksesan yang baik dalam komunikasi pemasarannya (Putri, 2018). Sebuah penelitian yang dilakukan di kota Makassar juga menunjukkan bahwa terdapat pengaruh yang signifikan dari pengunaan media digital terhadap jumlah penjualan. Semakin intens media digital digunakan, maka penjualan dari produk juga akan semakin meningkat (Ayuni et al., 2019).

Berdasarkan dari hasil penelitian yang dilakukan Digital in Asia, lebih dari 3 dari 7,5 miliar orang yang ada dari seluruh penjuru dunia setiap bulannya menggunakan jejaring internet khususnya media sosial dalam kehidupannya. Delapan ratus juta orang menjadi pengguna aktif dari Instagram dengan pengguna terbanyak dalam rentang usia 18-34 tahun. Orang dari berbagai kalangan dan profesi telah menggunakan platform media sosial ini, bahkan termasuk profesi seperti dokter untuk berinteraksi dengan para pasiennya (Sapoetri \& Pannindriya, 2019). Indonesia merupakan negara tertinggi ketiga yang menggunakan Instagram sebagai salah satu platform yang digemari oleh banyak kalangan. Instagram tidak hanya sebagai platform berbagi foto dan video saja, namun merupakan peluang besar sebagai media promosi yang sangat potensial. Instagram juga memiliki kemampuan untuk mengglobalkan informasi yang dulunya hanya diketahui oleh orang-orang lokal (Indika \& Jovita, 2017). Hal ini pernah dibahas dalam penelitian tentang sebuah akun Instagram yang 
mempromosikan pariwisata di Kota Malang. Akun Instagram ini membagikan foto, video dan informasi mengenai wisata-wisata lokal di Kota Malang. Dampak dari penyebaran informasi tersebut melalui Instagram, membuat lokasilokasi wisata yang dulunya hanya diketahui warga lokal, dapat tersebar luas baik ke wisatawan dalam negeri maupun wisatawan manca negara (Lantif et al., 2019).

Dengan perubahan budaya konsumen pengguna teknologi yang signifikan, industri harus memanfaatkan keadaan dengan baik, yakni melakukan promosi dengan strategi digital marketing communication agar dapat menarik minat pelanggan melalui jejaring internet dan kemajuan teknologi. Saat ini bahkan perusahaan yang bersifat tradisional pun mulai beralih ke pemasaran digital guna mempertahankan daya saing dengan perusahaan yang lebih modern (Mohansyah \& Parani, 2018). Digital marketing communication dapat menghubungkan dengan pelanggan dari seluruh penjuru dunia. Lingkup yang sangat luas menjadikan digital marketing communication ini sebagai kegiatan promosi yang efisien karena sekaligus dapat merambah pasar secara global tanpa dibatasi oleh waktu maupun geografis. Tren pemasaran modern ini lebih prospektif karena calon pelanggan potensial dapat dituju dengan penerapan strategi dan inovasi yang tepat (Purwana et al., 2017). Salah satu perusahaan yang telah berhasil berkembang dengan menggunakan strategi digital marketing communication adalah Lazada Indonesia. Perusahaan ini memfokuskan strategi komunikasi pemasarannya melalui platform digital dan berhasil menarik konsumen melalui strategi tersebut (Reza, 2016). Selain Lazada, penelitian pada situs jual beli online Bukalapak juga menunjukkan bahwa ada pengaruh dari pelayanan digital terhadap kepercayaan konsumen. Pelayanan melalui media digital terbukti meningkatkan kepercayaan dari pelanggan, dimana kepercayaan ini akhirnya bermuara pada peningkatan reputasi perusahaan (Boer \& Hendrastuti, 2018). Bahkan bukan hanya perusahaan-perusahaan berbasis online yang menjalankan strategi digital marketing communication. Perusahaan media mainstream seperti Net TV juga menggunakan berbagai media digital untuk menghadapi persaingan bisnis. NET TV menggunakan berbagai platform digital seperti media sosial (Twitter, Instagram, Facebook, LinkedIn, Youtube, dan Google +) dank anal digital Zulu.id. Keberadaan mediamedia digital tersebut adalah untuk menjangkau khalayak yang lebih luas dan membuat engagement dengan para pemirsanya. Pemanfaatan teknologi digital ini terbukti efektif dan bermanfaat untuk menjaga kelangsungan bisnis TV swasta tersebut (Permana \& Mahameruaji, 2019).

Industri perhotelan juga merupakan salah satu industri yang terdampak oleh perubahan dalam penggunaan media digital di masyarakat. Salah satu penelitian yang dilakukan di sebuah hotel di Subang, Jawa Barat menunjukkan bahwa media digital memberikan pengaruh besar terhadap interaksi antara pihak hotel dengan publiknya. Media digital dapat digunakan untuk melakukan interaksi dengan customer maupun potential customer, sehingga pihak hotel memahami tren terkini yang diminati masyarakat (Ruliana et al., 2019). Penelitian lain di sebuah hotel di Kuta Bali juga menunjukkan bahwa fitur-fitur yang ada pada media digital turut membantu komunikasi pemasaran dari hotel tersebut. Fitur-fitur media digital seperti adanya search engine, komunitas virtual, cookies, dan personal chatting dapat digunakan untuk menarik konsumen, menjalin relasi dengan konsumen, untuk mempelajari perilaku konsumen, maupun untuk membangun hubungan personal dengan konsumen (Nirmala, 2017).

Terdapat salah satu hotel yang menangkap fenomena-fenomena perubahan perilaku sosial di masyarakat Indonesia tersebut dengan cara mengembangkan strategi promosi melalui digital marketing communication yaitu Golden Tulip Legacy Surabaya. Dalam menjawab tantangan era postmodern yang membuat pola konsumsi berubah, maka Golden Tulip Legacy bersama-sama dengan peneliti melakukan perancangan pengelolaan website dan Instagram. Kedua jejaring tersebut merupakan akses penyaluran informasi utama dari Golden Tulip Legacy Surabaya karena dipengaruhi oleh perubahan pola pencarian 
informasi masyarakat yang menggunakan kedua jenis media tersebut.

\section{METODE PENELITIAN}

Penelitian ini menggunakan metode kualitatif deskriptif yang memfokuskan proses interaksi antara peneliti dengan peristiwa yang ada untuk memahami peristiwa tersebut secara alamiah. Metode pengumpulan data dilakukan dengan observasi, wawancara, dan dokumentasi. Observasi dilakukan pada website dan Instagram dari Golden Tulip Legacy Surabaya untuk mengetahui secara lebih mendalam aktivitas yang dilakukan selama ini. Selain itu, peneliti juga melakukan observasi pada website dan Instagram dari industri sejenis sebagai bahan pertimbangan peneliti untuk melakukan perancangan strategi digital marketing communication yang inovatif bagi Golden Tulip Legacy Surabaya. Sedangkan wawancara, menggunakan teknik wawancara mendalam dengan narasumber. Wawancara mendalam bersifat tidak kaku, tidak terstruktur, tidak baku, serta terbuka dengan dilakukannya pertemuan langsung secara intensif untuk memahami pandangan narasumber terkait dengan masalah penelitian yang dibahas. Terdapat lima orang informan yang menjadi narasumber wawancara yaitu Marketing Communication Golden Tulip Legacy Surabaya, Graphic Designer Golden Tulip Legacy Surabaya, IT Golden Tulip Legacy Surabaya, satu orang pelanggan Golden Tulip Legacy Surabaya, dan seorang ahli Digital Marketing Communication. Kemudian dokumentasi yang digunakan dalam penelitian ini berupa screen capture hasil observasi peneliti terhadap website dan Instagram Golden Tulip Legacy Surabaya.

Analisis data penelitian dilakukan melalui tiga tahapan yaitu reduksi data, pemaparan data, serta penarikan kesimpulan dan verifikasi. Pengujian validitas dilakukan dengan teknik triangulasi. Triangulasi dikenal sebagai istilah pengecekan data dengan mempergunakan beberapa sumber, teknik, dan waktu. Peneliti dapat menggunakan lebih dari satu sumber guna mendapatkan hasil apakah data yang diperoleh selama penelitian benar atau tidak. Dalam penelitian ini berfokus menggunakan triangulasi sumber untuk menguji kredibilitas data yang didapatkan oleh peneliti dengan membandingkan antara sumber data yang satu dengan sumber data lainnya dengan mengacu pada teori dan data yang didapatkan dari Ahli Digital Marketing Communication, Kumolo, yang telah menjadi pengelola dari digital marketing communication pada perusahaan media IDN Times. Selanjutnya, data dianalisis hingga menghasilkan kesimpulan penelitian.

\section{HASIL DAN PEMBAHASAN}

\section{Strategi Pengelolaan}

Era digital telah mendorong penggunaan platform komunikasi alternatif dalam melakukan komunikasi pemasaran terpadu (Dagumboy, 2019). Maka dari itu, berdasarkan hasil wawancara dengan narasumber dirancang strategi pengelolaan yang tepat untuk digital marketing communication. Dalam hal waktu pengelolaan harus dilakukan secara harian dan berisi informasi-informasi detail terkait dengan hotel. Strategi pengelolaan juga dapat menekankan pada jenis marketing communication 3.0 dimana strategi difokuskan kepada masyarakat, atau para pengguna dari platform digital marketing. Karena strategi pemasaran yang berpusat pada pengguna akan menghasilkan dampak yang positif juga terhadap perusahaan (Indrayani \& Sunarto, 2019). Selain itu, pengelola juga harus memfokuskan strategi pada platform yang berpotensial besar dalam memberikan kontribusi untuk pencapaian tujuan perusahaan. Strategi pengelolaan perlu dilakukan agar pengelola dapat menentukan ke arah mana bisnis akan berjalan dan menentukan bagaimana untuk mencapai tujuan perusahaan. Dengan adanya strategi pengelolaan yang lebih terstruktur, penggunaan digital marketing communication dapat mencapai tujuan yang telah ditetapkan oleh Golden Tulip Legacy Surabaya, yakni mendapatkan pelanggan dari berbagai penjuru. Maka dari itu, tim manajemen Golden Tulip Legacy Surabaya bersama dengan peneliti merancang strategi pengelolaan yang 
terstruktur dengan timeline yang sudah disepakati bersama.

Langkah-langkah yang digunakan untuk menciptakan strategi pengelolaan digital marketing communication Golden Tulip Legacy Surabaya adalah dengan menganalisis IFAS (Internal Strategic Factor Analysis Summary) dan EFAS (External Strategic Factor Analysis Summary). Analisis strategi ini lebih dikenal dengan analisis SWOT atau analisis Strength, Weakness, Opportunity, Threat (Elyarni, 2016). Setelah analisis SWOT selesai dilakukan, pengelola mencari titik temu yang dapat dikembangkan untuk memberikan nilai kepada pelanggan. Lalu, pengelola membuat rencana pemasaran berdasarkan dari strategi SWOT yang telah dilakukan. Pada umumnya, rencana pemasaran dibuat untuk kurun waktu satu tahun. Pembuatan rencana pemasaran ini harus mengarah pada visi dari perusahaan dengan pembuatan rencana-rencana strategis untuk pemasaran yang akan dilakukan. Penetapan rencana dibuat dalam bentuk Kalender Pengelolaan yang disesuaikan dengan kebutuhan dari perusahaan. Pengelola membuat Kalender Pengelolaan bulanan dengan penetapan rencana yang telah didiskusikan dengan pihak top manajemen Golden Tulip Legacy Surabaya. Pembuatan kalender dilakukan dengan mencari kegiatan dan atau hari penting nasional maupun internasional. Selain itu, pengelola membuat Kalender Perencanaan Konten terlebih dahulu untuk mempermudah pembuatan Kalender Pengelolaan Bulanan.

Dengan mengklasifikan kegiatan utama dan hari nasional atau internasional setiap bulan akan lebih memudahkan pengelola untuk menemukan dan membuat konten yang akan digunakan sebagai digital marketing communication Golden Tulip Legacy Surabaya. Satu ide kegiatan utama dapat dibedah menjadi beberapa ide dan strategi konten yang disesuaikan dengan tujuan perusahaan. Pengelola juga akan lebih mudah dalam pembuatan Kalender Pengelolaan yang memiliki detail rinci perencanaan yang harus dilakukan dengan acuan garis besar ide konten setiap bulan.

Supaya pelanggan menyadari keberadaan perusahaan dan tujuan-tujuan yang telah ditetapkan perusahaan dapat tercapai, pengelola harus melakukan implementasi strategi pengelolaan setiap hari dengan minimal satu hingga tiga unggahan. Pembuatan kalender pengelolaan dapat digunakan agar pengelola mengetahui materi apa yang akan diunggah setiap hari dan di jam berapa materi tersebut harus diunggah. Alangkah baiknya apabila pengelola dapat mengunggah di jam-jam tertentu yang banyak pengguna mengakses Instagram seperti pada jam makan siang atau jam menjelang tidur di malam hari. Pembuatan Kalender Pengelolaan Digital Marketing Communication Harian dapat dilihat seperti contoh berikut:

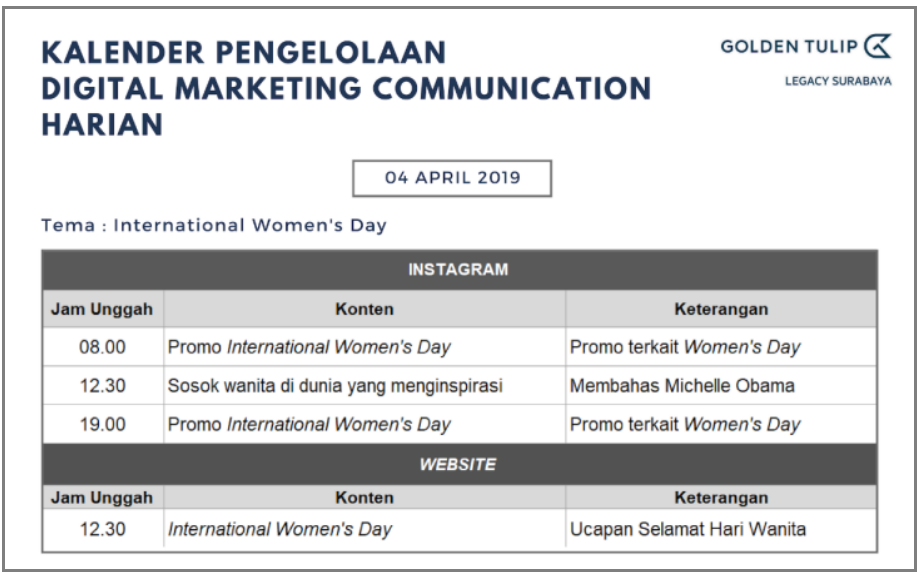

\section{Gambar 1. Contoh Kalender Pengelolaan Digital Marketing Communication Harian} Sumber: Diolah peneliti (2019) 
Untuk memastikan seluruh digital marketing communication Golden Tulip Legacy Surabaya sudah berjalan dengan rutin, pengelola mengisi daftar periksa atau checklist yang perlu dilakukan setiap hari. Checklist dapat dilaporkan kepada manajer atau pihak atasan lain yang memiliki wewenang untuk mengoreksi sistem pengelolaan yang telah dijalankan. Agar konten yang dibuat terstruktur dan tidak menimbulkan kejenuhan, maka dapat dibuat sistem perumusan konten. Sistem yang dibuat peneliti mengacu agar pengelola memiliki arah yang jelas dalam pengelolaan digital marketing dan memudahkan dalam peluncuran desain konten. Sistem perumusan konten ini dibuat sekaligus untuk mendapatkan persetujuan dari semua departemen dalam Golden Tulip Legacy Surabaya, agar setiap saran dan kritik dapat langsung diutarakan saat proses rapat berlangsung sehingga Graphic Designer akan membuat opsi desain berdasarkan rancangan konten yang sudah pasti. Sedangkan beberapa strategi inovatif yang digunakan untuk meningkatkan digital marketing communication Golden Tulip Legacy Surabaya antara lain:

1) Memberikan kuis sederhana berhadiah bagi pengguna yang dapat menebak dengan benar pertanyaan yang diajukan dengan menyediakan hadiah seperti voucher pulsa atau voucher discount

2) Memberikan hadiah atau yang dikenal dengan giveaway bagi pengguna yang menerima tantangan yang diberikan oleh pengelola Golden Tulip Legacy Surabaya, seperti contoh berikut:

3) Memberikan promo flash sale dengan potongan harga yang fantastis sehingga dapat membuat pelanggan menantikan flash sale yang sedang berlangsung, seperti contoh berikut:

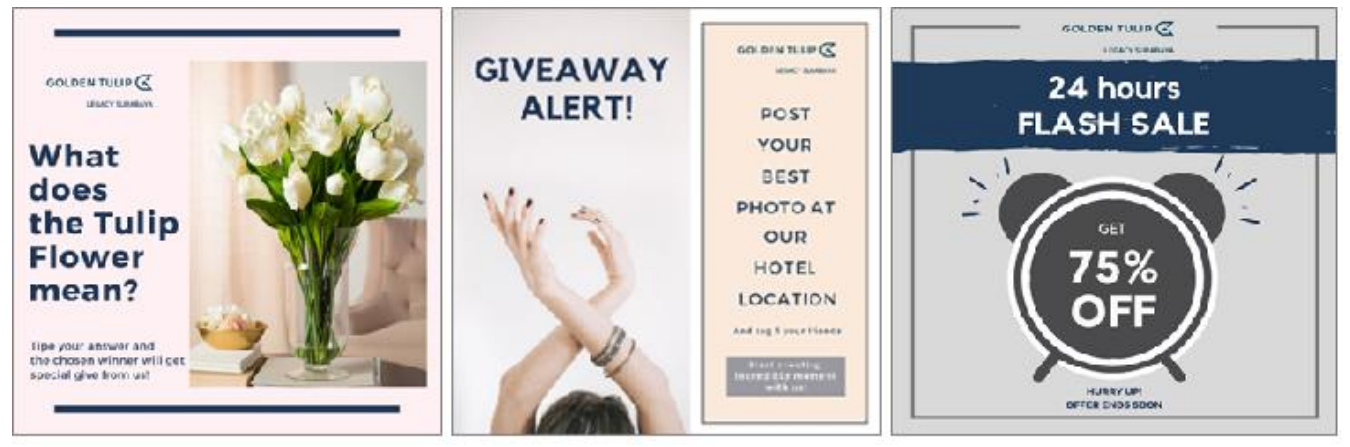

Gambar 2. Contoh Unggahan Berdasarkan Startegi Inovatif

Sumber: Diolah peneliti (2019)

\section{Website}

Agar website dapat digunakan sebagai alternatif pemasaran secara global, website harus memiliki kriteria untuk pengguna dapat terlibat langsung dalam berinteraksi dengan perusahaan. Penelitian terdahulu yang berjudul "Pembuatan Sistem Informasi Penjualan Berbasis Web Untuk Memperluas Pangsa Pasar" menunjukkan bahwa adanya sistem informasi dalam bentuk website dapat meningkatkan penjualan dari perusahaan dan menjangkau pangsa pasar yang lebih luas (Kosasi, 2014). Maka dari itu, untuk website dari Golden Tulip Legacy Surabaya perlu adanya penambahan fitur untuk live chat, di mana pelanggan dapat langsung melakukan interaksi untuk menanyakan dan mengonfirmasi hal yang dibutuhkan. Website Golden Tulip Legacy Surabaya juga dapat dilengkapi dengan penambahan fitur $Q R$ Code agar pengguna dapat memindai kode tersebut untuk lebih mudah terhubung dengan customer service atau customer care hotel dan berinteraksi secara langsung. Kelengkapan informasi menjadi faktor penunjang yang dapat membuat pelanggan semakin yakin terhadap suatu hal. Perusahaan di bidang jasa seperti industri perhotelan memungkinkan untuk mendapatkan pelanggan dari berbagai penjuru dunia. Oleh karena itu, pelanggan membutuhkan informasi terkait dengan fasilitas, keunggulan hotel, termasuk 
informasi umum mengenai lokasi hotel dan sekitarnya. Website dari Golden Tulip Legacy Surabaya sudah berisikan informasi yang cukup lengkap mengenai fasilitas dan keunggulan hotel, namun informasi umum mengenai lokasi hotel dan sekitarnya hanya dijelaskan dalam beberapa kalimat. Pelanggan tidak dapat mengetahui peta lokasi di mana hotel berada dan lokasi-lokasi apa saja yang terdapat di sekitar hotel, sehingga apabila pelangan perlu untuk mencari tahu lokasi hotel dengan lokasi lainnya seperti pusat perbelanjaan, tempat wisata, ataupun tempat makan, pelanggan harus mencari informasi di luar dari website Golden Tulip Legacy Surabaya. Dalam peta lokasi juga dapat ditambahkan informasi mengenai opsi akses dan transportasi yang dapat digunakan, sehingga pelanggan akan mendapatkan gambaran mengenai perjalanan mereka. Maka dari itu, untuk website dari Golden Tulip Legacy Surabaya perlu adanya penambahan fitur untuk peta lokasi. Tampilan website juga menjadi faktor yang harus diperhatikan oleh perusahaan karena semakin mudah digunakan, maka akan membuat pelanggan melihat bahwa perusahaan memiliki nilai tambah. Sebagai akses penyaluran informasi utama dari Golden Tulip Legacy Surabaya, website harus memiliki tampilan yang dapat disesuaikan dengan berbagai perangkat seperti desktop komputer atau laptop maupun seluler. Dengan tampilan yang kompatibel di berbagai perangkat, pengguna akan merasa mudah untuk mencari informasi yang dibutuhkan. Didukung dengan kecanggihan teknologi yang semakin modern, pengguna akan lebih merasa terbantu dengan adanya fitur Virtual Tour yang dapat memberikan pengalaman lebih kepada penggunanya. Pengguna dapat mengetahui keadaan yang sesungguhnya dengan melakukan survei secara tidak langsung melalui fitur Virtual Tour. Maka dari itu, akan lebih baik apabila website dari Golden Tulip Legacy Surabaya terdapat fitur untuk Virtual Tour.

Selain itu, website juga harus efektif dalam mengajak pengguna dengan memberikan informasi terkait dengan produk atau layanan yang ditawarkan. Golden Tulip Legacy Surabaya sudah tepat dalam penempatan kolom reservasi yang terdapat pada bagian atas website, karena kolom reservasi secara tidak langsung mengarahkan pengguna untuk melakukan reservasi. Berdasarkan dari wawancara yang telah dilakukan dengan narasumber dan didukung oleh pengamatan peneliti, dalam website Golden Tulip Legacy Surabaya tidak tersedia ajakan untuk pengguna membeli produk atau promo-promo yang tersedia. Pop-up info merupakan salah satu strategi interaktif karena memberikan informasi secara langsung kepada pelanggan yang membuka website dan sekaligus mengarahkan pelanggan untuk melakukan transaksi. Maka dari itu, akan lebih baik apabila website dari Golden Tulip Legacy Surabaya terdapat informasi yang berisi ajakan untuk membeli produk atau promo-promo yang tersedia dalam bentuk pop-up info, seperti pada tampilan sebagai berikut:

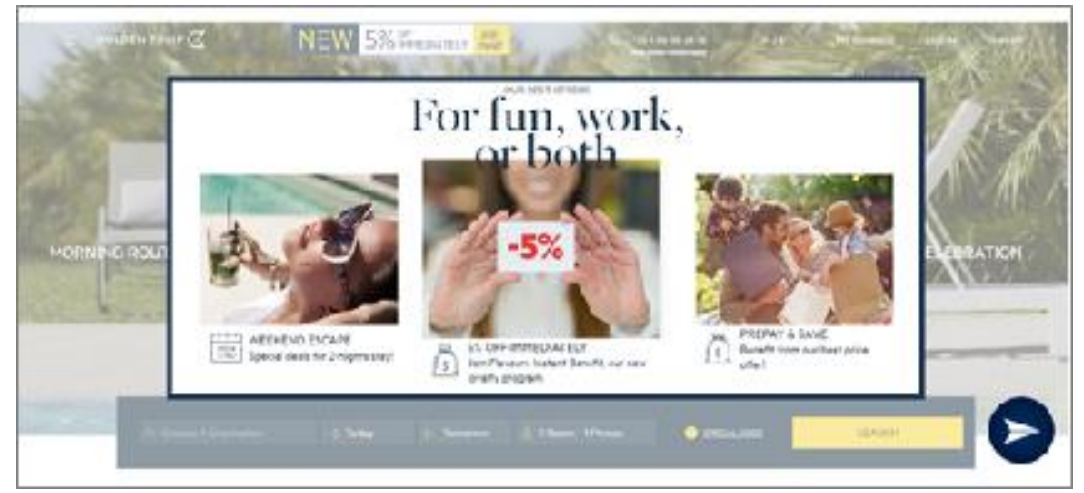

Gambar 4. Contoh Pop-Up Info dalam Website Sumber: Diolah peneliti (2019) 
Dengan membuat website Golden Tulip Legacy Surabaya berdasarkan seluruh kriteria akan menjadikan alternatif pemasaran yang informatif bagi pengguna dan jika seluruh kriteria dari website dapat terpenuhi, maka website akan membantu perusahaan untuk merepresentasikan gambaran dari perusahaan (eMarketing Institute, 2018). Hal ini juga akan memenuhi ekspektasi dari Marketing Communication dan Graphic Designer yang menginginkan website dapat merepresentasikan hotel bintang lima yang mewah dan elegan serta agar dapat menarik minat pelanggan untuk menginap di Golden Tulip Legacy Surabaya.

\section{Instagram}

Media sosial Instagram yang dapat digunakan oleh semua orang untuk berbagi foto dan video melalui perangkat menjadi salah satu alat promosi yang sangat potensial (Indika \& Jovita, 2017). Golden Tulip Legacy Surabaya menggunakan Instagram sebagai salah satu fokus dalam menjalankan digital marketing communication. Berdasarkan dari hasil wawancara dengan narasumber dan pengamatan yang dilakukan peneliti, unggahan foto yang terdapat dalam Instagram Golden Tulip Legacy Surabaya sudah menunjukkan resolusi gambar yang tinggi dan pencahayaan yang terang, meskipun masih belum menerapkan unggahan yang dapat membangkitkan emosi dari penggunanya.

Unggahan dalam Instagram akan terlihat mengesankan apabila unggahan terlihat natural. Efek filter yang berlebihan hanya akan membuat unggahan terkesan tidak asli. Berdasarkan dari hasil wawancara dengan pengelola Instagram Golden Tulip Legacy Surabaya, selama ini unggahan yang sudah dilakukan tidak menggunakan efek filter. Hal ini sejalan dengan pendapat Ahli Digital Marketing Communication bahwa tidak perlu menggunakan efek filter dalam unggahan Instagram. Maka dari itu, pengelola Instagram Golden Tulip Legacy Surabaya dapat mengunggah gambar yang membangkitkan emosi seperti konten mengenai humor, motivasi, tips, trik, kenangan, dan lain-lain tanpa menggunakan efek filter yang berlebihan.
Unggahan yang hanya disertai petunjuk dan bersifat ajakan seperti contoh konten foto di atas akan membuat pelanggan merasa ingin tahu apa yang dimaksud dengan kata 'try $m e$ ' atau 'coba saya' dan hanya tampilan irisan jeruk dan lemon. Dengan rasa penasaran dari unggahan foto tersebut, pelanggan akan mencari tahu apa yang dimaksud dari inti unggahan tersebut. Maka dari itu, unggahan yang dapat membangkitkan emosi, memberikan rasa penasaran, dan tanpa efek filter yang berlebihan akan menarik atensi para pelanggan.

Penggunaan hastag dalam suatu unggahan menjadi salah satu pengkategorian bagi pengguna dan pengelola untuk lebih mudah dalam mencari unggahan. Dalam Instagram Golden Tulip Legacy Surabaya penggunaan hastag sudah diterapkan, namun penggunaan hastag yang dilakukan belum terstruktur dalam hal pengkategorian. Berdasarkan dari hasil wawancara yang dilakukan dengan Marketing Communication selaku pengelola Instagram Golden Tulip Legacy Surabaya, narasumber terlihat ragu-ragu saat menjelaskan mengenai penggunaan hastag. Pada awalnya, narasumber menjelaskan hanya menggunakan satu hastag, lalu narasumber menjelaskan lagi bahwa 'mungkin' terdapat hastag lainnya. Peneliti menyimpulkan berdasarkan hasil wawancara dan observasi yang telah dilakukan, penggunaan hastag dalam Instagram Golden Tulip Legacy Surabaya sudah menggunakan lebih dari satu hastag, namun masih tidak terkategori. Pengelola Instagram Golden Tulip Legacy Surabaya juga tidak menyatakan adanya pengkategorian hastag yang disesuaikan dengan konten foto yang akan diunggah. Penggunaan hastag harus dipertimbangkan dengan baik karena penggunaan yang berlebihan akan terlihat tidak profesional. Maka dari itu, unggahan dalam Instagram Golden Tulip Legacy Surabaya perlu menggunakan beberapa hastag khusus yang spesifik dalam setiap unggahannya agar pengikut dalam Instagram dapat dengan mudah mengingat hastag yang menjadi pengkategorian dari Golden Tulip Legacy Surabaya. Dengan memiliki pengkategorian hastag untuk setiap unggahan akan memudahkan pengelola saat melakukan proses pengunggahan. Hastag dapat 
disesuaikan dengan berbagai unggahan yang menjadi konten dari Instagram Golden Tulip Legacy Surabaya. Dengan hastag spesifik yang dibuat per kategori, pengelola dapat mengetahui berapa jumlah unggahan di Instagram terkait kategori dari hastag. Selain itu, dengan adanya hastag juga akan membuat pengelola lebih mudah menelusuri unggahan yang sesuai dengan kategori pencarian.

Mengunggah konten yang menarik bukanlah hal yang mudah. Diperlukan berbagai strategi pengelolaan konten agar dapat mempertahankan dan menjangkau pengguna Instagram. Pengelola dan perancang konten foto atau video harus terus mencari inspirasi baru untuk terus menghadirkan konten yang menarik. Inspirasi dapat ditemukan dari berbagai sumber, salah satunya dari Instagram Explore. Hasil pencarian dari Instagram Explore akan menampilkan kontenkonten yang sedang kekinian, sehingga pengelola akan mendapatkan banyak inspirasi baru terkait dengan tren yang sedang berlangsung. Selain itu, Kumolo selaku Ahli Digital Marketing Communication juga menyatakan bahwa pengelola perlu bertukar pikiran dengan tim sehingga akan menghasilkan rancangan konten yang menarik. Untuk mendapat inspirasi dalam membuat konten di Instagram, pengelola dapat memanfaatkan polling dalam fitur Instagram Story yang dapat mengundang engagement dari followers. Kelebihan dari menggunakan fitur polling ini, pengelola dapat mengetahui konten yang diinginkan oleh followers. Pengelola dapat membuat polling dalam Instagram Story. Untuk mengetahui keinginan followers, pengelola juga dapat memanfaatkan fitur pertanyaan yang tersedia dalam Instagram Story. Dengan menggunakan fitur ini, pengelola akan mendapatkan beberapa jawaban dari followers aktif Instagram Golden Tulip Legacy Surabaya yang berpartisipasi menjawab dalam kolom pertanyaan yang disediakan. Pengelola dapat memberikan pertanyaan interaktif seperti:

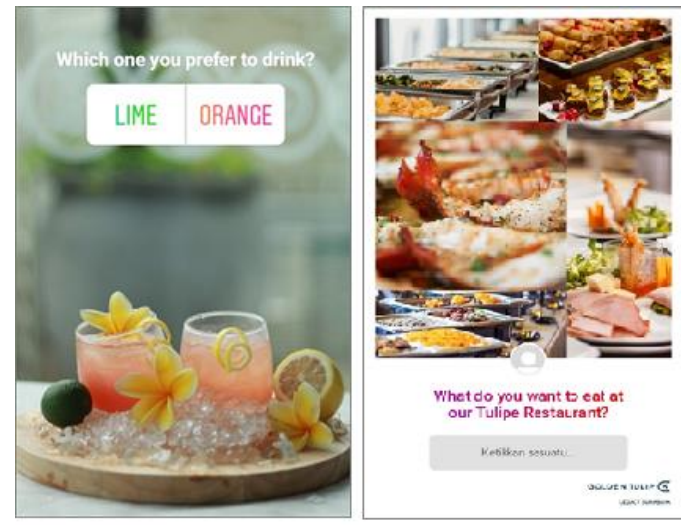

\section{Gambar 5. Contoh Polling dan Pertanyaan dalam Instagram Story Sumber: Diolah peneliti (2019)}

Instagram dengan akun bisnis perlu untuk menjaga hubungan dengan followers dengan cara mengunggah konten secara teratur. Followers yang tetap terlibat akan menunjang keberlangsungan akun Instagram perusahaan. Sementara itu, apabila akun Instagram tidak aktif dalam jangka waktu yang cukup lama akan menyebabkan hilangnya followers. Berdasarkan dari hasil wawancara dan observasi yang telah dilakukan, pengelolaan unggahan dalam akun Instagram Golden Tulip Legacy Surabaya masih belum dilakukan secara rutin. Ahli Digital Marketing Communication menyatakan bahwa unggahan dalam media sosial disarankan sebanyak tiga hingga lima unggahan dalam setiap hari. Followers perlu dijaga agar tetap menjadi pengikut akun Instagram perusahaan dengan cara melakukan pengunggahan dengan frekuensi sekali atau dua kali dalam setiap hari secara teratur. Sedangkan unggahan yang seharusnya dilakukan untuk industri perhotelan cukup dalam frekuensi satu hingga tiga 
unggahan dalam setiap hari, karena unggahan yang terlalu banyak akan menjadi spam. Pengelola dapat membuat kalender pengelolaan Instagram harian untuk membantu mengorganisir jadwal unggahan, sehingga pengelola sudah mengetahui konten apa saja yang akan diunggah dan dapat mempersiapkan kebutuhan untuk unggahan.

Interaksi antara perusahaan dan pelanggan menjadi salah satu kegiatan utama dalam dunia bisnis. Berdasarkan masukan dari Ahli Digital Marketing Communication, fitur Instagram Direct dapat berfungsi sebagai customer service atau customer care. Dengan adanya fitur Instagram Direct, Golden Tulip Legacy Surabaya dapat memanfaatkan fitur ini untuk melakukan interaksi dengan pelanggan. Instagram Direct menyediakan layanan untuk saling berkirim pesan secara langsung antar pengguna Instagram. Fitur ini juga memungkinkan pengguna untuk melakukan pengiriman foto maupun video. Hal ini akan mendukung perusahaan untuk dapat menjalin hubungan baik dengan pelanggan seperti mengirimkan pesan ucapan terima kasih atau pesan informatif seperti pemberitahuan promo dan lain sebagainya. Interaksi yang dilakukan dengan pengguna akan memberikan masukan baru untuk perusahaan. Followers Instagram juga kerap kali akan meninggalkan komentar dalam kolom komentar unggahan Instagram apabila konten menarik atensi followers. Dengan membalas komentar yang telah ditinggalkan dalam unggahan, followers akan merasa dihargai oleh perusahaan. Dalam akun Instagram Golden Tulip Legacy Surabaya, beberapa komentar yang ditinggalkan oleh followers masih sering tidak dibalas oleh pengelola. Maka dari itu, Golden Tulip Legacy Surabaya perlu untuk menyediakan satu admin khusus yang mengelola dan menanggapi komentar maupun pesan dari followers. Selain itu, pengelola Instagram Golden Tulip Legacy Surabaya dapat menyediakan beberapa kalimat balasan yang sekiranya sering digunakan untuk berinteraksi dengan pengguna Instagram dalam fitur Instagram Direct dan kolom komentar Instagram.
Akun Instagram yang memiliki followers dalam jumlah yang banyak akan terlihat terpercaya. Followers dari akun Instagram Golden Tulip Legacy Surabaya per 29 Desember 2018 berjumlah 2.191 followers. Berdasarkan dari hasil wawancara yang telah dilakukan, pengelola Instagram Golden Tulip Legacy Surabaya menyatakan bahwa akun Instagram asli dan tidak pernah melakukan pembelian followers. Hal ini juga didukung oleh Ahli Digital Marketing Communication bahwa pembelian followers bukanlah hal yang tepat untuk dilakukan. Maka dari itu untuk meningkatkan jumlah followers digunakan strategi-strategi khusus seperti yang telah dibahas sebelumnya agar mendapatkan atensi dari pengguna Instagram. Pembelian followers dihindari karena akun Instagram akan menjadi palsu dengan banyaknya followers yang semu. Followers yang didapatkan dari 'membeli' tidak akan memberikan interaksi maupun transaksi bisnis.

Berdasarkan dari hasil wawancara, selama ini pengelola membalas komentar followers Instagram dengan positif dan sopan, kecuali untuk komentar yang menawarkan produk atau jasa dari followers. Kumolo, selaku Ahli Digital Marketing Communication juga menyarankan bahwa sebagai perwakilan dari pihak hotel, segala kesalahan baik yang dibuat oleh pihak manajemen hotel maupun kesalahan dari pelanggan, pengelola harus meminta maaf atas kejadian yang membuat pelanggan merasa tidak nyaman dengan menanggapi secara sopan dan tidak menyalahkan. Sebagai platform yang digunakan untuk berinteraksi dengan pengguna, Instagram dapat menjadi ruang untuk pengguna mengungkapkan pujian maupun kritikan. Pengelola harus selektif dalam memberikan tanggapan kepada pengguna Instagram karena berinteraksi dengan menggunakan pesan publik yang dapat dibaca oleh khalayak umum dapat berdampak positif dan negatif. Untuk komentar yang berisi kritikan atau protes dari followers di Instagram, pengelola harus memberikan tanggapan yang tepat dengan tidak terkesan menyalahkan. Fokus dalam manajemen pemasaran harus mengarah pada kepuasan pelanggan yang didasarkan pada kebutuhan dan 
keinginan dari pelanggan. Pengelola dapat menanggapi komentar yang memuat kritikan tersebut dengan baik dan sopan, mencari akar permasalahannya, mengonfirmasi dengan pihak yang terkait, dan memberikan solusi kepada follower tersebut.

Mengikuti perkembangan tren perlu untuk dilakukan agar konten yang diunggah dapat sesuai dengan keadaan yang terkini. Berdasarkan dari hasil wawancara yang telah dilakukan dengan pengelola Instagram Golden Tulip Legacy Surabaya, perkembangan tren Social Influencer sangat diterima dengan baik, meskipun strategi ini masih belum diimplementasikan oleh Golden Tulip Legacy Surabaya. Dengan mengikuti perkembangan tren dapat meningkatkan followers serta mendapatkan calon pelanggan yang potensial karena menunjukkan bahwa akun Instagram aktif dan mengikuti perkembangan zaman. Berdasarkan dari hasil wawancara yang telah dilakukan dengan Graphic Designer Golden Tulip Legacy Surabaya, desain yang digunakan untuk konten promosi digital marketing communication lebih disesuaikan dengan tema dan acaranya yang sudah dirancangkan oleh tim, dan tidak mengikuti perkembangan tren desain yang terkini. Menurut Graphic Designer Golden Tulip Legacy Surabaya, perkembangan tren desain dapat digunakan sebagai referensi apabila tidak memiliki inspirasi baru. Menurut pelanggan Golden Tulip Legacy Surabaya, perkembangan tren haruslah dilakukan untuk mengelola digital marketing communication agar dapat menarik perhatian dari followers Instagram. Pernyataan pelanggan Golden Tulip Legacy Surabaya ini juga sejalan dengan pendapat dari Kumolo selaku Ahli Digital Marketing Communication bahwa tren tidaklah untuk dilawan, namun pengelola harus senantiasa berkawan dengan tren. Maka dari itu, Graphic Designer Golden Tulip Legacy Surabaya juga harus tetap mengikuti perkembangan tren agar dapat menghasilkan konten untuk digital marketing communication yang sesuai dengan keadaan terkini.

Pengelola Instagram Golden Tulip Legacy Surabaya dapat menggunakan rancangan Timeline Instagram dengan pengaturan feed yang disesuaikan dengan warna atau taste dari Golden Tulip Legacy Surabaya sehingga tampilan Instagram akan terlihat bagus dan menarik. Selain itu, dari penelitian terdahulu yang berjudul "Media Sosial Instagram Sebagai Sarana Promosi Untuk Meningkatkan Minat Beli Konsumen" menemukan bahwa foto yang dikomunikasikan dan dikemas secara kreatif dalam media sosial Instagram menjadi pertimbangan yang penting untuk menarik minat beli konsumen (Indika \& Jovita, 2017). Maka dari itu, pengelola Instagram Golden Tulip Legacy Surabaya dapat membuat Timeline Instagram dengan pengaturan feed seperti contoh berikut:

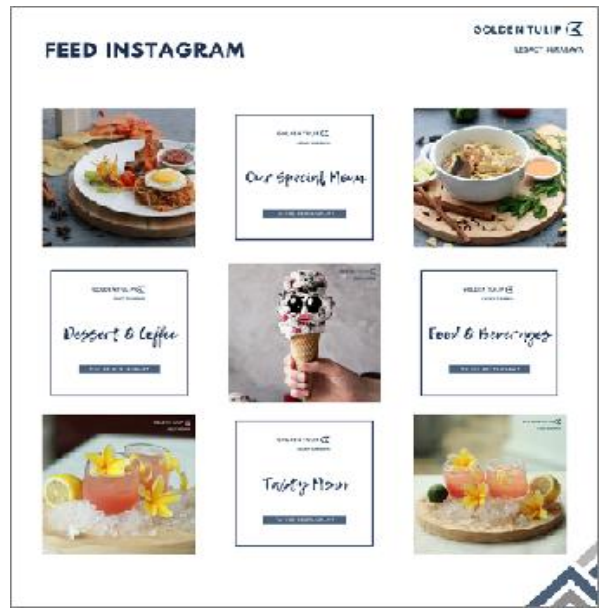

Gambar 6. Contoh Feed Instagram yang Menarik Sumber: Diolah peneliti (2019) 
Strategi lain yang dapat digunakan untuk meningkatkan traffic pengunjung Instagram Golden Tulip Legacy Surabaya antara lain:

1) Menggunakan Instagram $A d s$ agar dapat muncul dalam Instagram pengguna yang melakukan pencarian terkait dengan hotel;

2) Mengundang Social Influencer atau Selebgram untuk mengulas hotel maupun promo yang ditawarkan;

3) Membuat video pemasaran terkait ulasan hotel, testimoni pelanggan, cuplikan kegiatan, dan lain sebagainya;

4) Menggunakan paid promote yang ditawarkan pihak lain untuk dipromosikan kepada followers aktif akun Instagram pengguna yang bersangkutan;

5) Mengunggah ulang atau me-repost unggahan yang ditandai oleh pengguna karena pengguna akan merasa dihargai saat unggahan mereka ditampilkan dalam Instagram Golden Tulip Legacy Surabaya. Memberikan teaser video yang dapat membuat pengguna ingin mengetahui lebih lanjut terkait dengan hal yang akan diunggah.

\section{SIMPULAN}

Menghadapi perubahan pola konsumsi dan pencarian informasi dari masyarakat yang berubah di era postmodern, Golden Tulip Legacy sebagai salah satu Hotel Bintang 5, bekerjasama dengan peneliti merancangkan strategi digital marketing communication. Hasil dari penelitian ini menunjukkan bahwa pengelolaan digital marketing communication Golden Tulip Legacy Surabaya sebagai media pemasaran dapat lebih efektif dan efisien dalam menjangkau pangsa pasar yang lebih luas jika memiliki strategi pengelolaan yang inovatif. Maka dari itu, digital marketing communication Golden Tulip Legacy Surabaya dirancangkan dalam hal strategi pengelolaan, yakni sebagai berikut:

1) Merencanakan kalender pengelolaan digital marketing communication tahunan, bulanan, dan harian dengan analisis strategi yang sudah direncanakan bersama dengan tim manajemen;
2) Mengoperasikan sistem perumusan konten agar pengelolaan digital marketing communication terlaksana dengan baik;

3) Membuat platform website dengan fitur-fitur yang dapat memudahkan pengguna mencari informasi seperti penambahan fitur live chat, $Q R$ Code, peta lokasi, virtual tour, dan popup info;

4) Mengoptimalkan Instagram dengan unggahan yang membangkitkan emosi, konten yang interaktif, dan disertai hastag;

5) Harus mengikuti tren yang sedang berlangsung agar pelanggan dapat tertarik dengan penawaran yang diberikan.

\section{DAFTAR PUSTAKA}

Anggraeni, D., Said, M., \& Febrina, D. (2019). Penggunaan Saluran Komunikasi Untuk Memenuhi Kebutuhan Informasi Wanita Pengusaha Kuliner Kota Depok. Jurnal Komunikasi Global, 8(1), 38-50.

Ayuni, Q., Cangara, H., \& Arianto, A. (2019). The Influence of Digital Media Use on Sales Level of Culinary Package Product Among Female Entrepreneur. Jurnal Penelitian Komunikasi Dan Opini Publik, 23(2), 129141.

https://doi.org/10.33299/jpkop.23.2.2382

Boer, R. F., \& Hendrastuti, R. V. (2018). Reputation Communication of Online Companies. Jurnal Komunikasi Ikatan Sarjana Komunikasi Indonesia, 3(1), 36-44. https://doi.org/10.25008/jkiski.v3i1.147

Dagumboy, E. C. (2019). Coverage index of various communication platforms: a segmented approach to philippine university marketing. Jurnal Studi Komunikasi (Indonesian Journal of Communications Studies), 3(3), 287-315. https://doi.org/10.25139/jsk.v3i3.1842

Elyarni, R. (2016). Analisis SWOT Terhadap Strategi Pemasaran Layanan SAP Express pada PT. SAP. Jurnal Metris, 17, 81-88. 
eMarketing Institute. (2018). E-Commerce Fundamentals: E-Commerce for beginners. eMarketing Institute.

Hargadon, A. (2015). How to discover and assess opportunities for business model innovation. Strategy and Leadership, 43(6), 33-37. https://doi.org/10.1108/SL-08-20150069

Ikeda, K., \& Marshall, A. (2016). How successful organizations drive innovation. Strategy and Leadership, 44(3), 9-19. https://doi.org/10.1108/SL-04-2016-0029

Ilham, I. (2018). Paradigma Postmodernisme; Solusi untuk Kehidupan Sosial? Jurnal Sosiologi USK (Media Pemikiran \& Aplikasi), 12(1), 1-23.

Indika, D. R., \& Jovita, C. (2017). Media Sosial Instagram Sebagai Sarana Promosi Untuk Meningkatkan Minat Beli Konsumen. Jurnal Bisnis Terapan, 1(01), 25-32. https://doi.org/10.24123/jbt.v1i01.296

Indrayani, H., \& Sunarto. (2019). Fandom: Marketing Communication Strategy 3 . 0 to Strengthen The Fantation of Nationalism Through Sports. Bricolage : Jurnal Magister Ilmu Komunikasi, 5(1), 15-30.

Kosasi, S. (2014). Pembuatan Sistem Informasi Penjualan Berbasis Web Untuk Memperluas Pangsa Pasar. Prosiding SNATIF, O(0), 225232.

Lantif, M. A. F., Nastiti, N. De, Hapsari, N. M., \& Fatimah, S. (2019). Branding Destinasi Wisata Gunung Bromo Melalui Instagram Sebagai Upaya Glokalisasi. Jurnal Pariwisata, 6(2), 108-115. https://doi.org/10.31311/par.v6i2.5583

Mohansyah, A., \& Parani, R. (2018). Digital Online Dan Trust Dalam Hubungan Antara Tokopedia Dengan Pengguna Layanan. LONTAR: Jurnal Ilmu Komunikasi, 6(1), $58-68$

https://doi.org/10.30656/lontar.v6i1.649
Nirmala, B. P. W. (2017). Persepsi Pengelola Hotel Bintang 1-5 Terhadap Fungsi Dan Fitur Media Pemasaran Online Di Kecamatan Kuta, Provinsi Bali. Jurnal Master Pariwisata (JUMPA), 3(2), 356371.

https://doi.org/10.24843/jumpa.2017.v03.i02 .p11

Permana, R. S. M., \& Mahameruaji, J. N. (2019). Strategi Pemanfaatan Media Baru Net. TV. Jurnal Studi Komunikasi Dan Media, 23(1), 21-36. https://doi.org/10.31445/jskm.2019.1770

Purwana, D., Rahmi, \& Aditya, S. (2017). Pemanfaatan Digital Marketing Bagi Usaha Mikro, Kecil, dan Menengah (UMKM) di Kelurahan Malaka Sari, Duren Sawit. Jurnal Pemberdayaan Masyarakat Madani, 1(1), $1-17$.

https://doi.org/doi.org/10.21009/JPMM.001. 1.01 .

Putri, V. K. A. (2018). Media Sosial Terintegrasi dalam Komunikasi Pemasaran Brand: Studi Komparasi Pemanfaatan Media Sosial Oleh High dan Low Involvement Decision Brand. Jurnal Komunikasi Indonesia, 4(2), 108115. https://doi.org/10.7454/jki.v4i2.8889

Reza, F. (2016). Strategi Promosi Penjualan Online Lazada.Co.Id. Jurnal Kajian Komunikasi, 4(1), 64-74. https://doi.org/10.24198/jkk.vol4n1.6

Ruliana, P., Lestari, P., \& Andrini, S. (2019). Model Komunikasi Korporat Sari Ater Hotel \& Resort Dalam Menghadapi Revolusi Industri 4.0. Jurnal ASPIKOM, 4(1), 60-82. https://doi.org/10.24329/aspikom.v4i1.535

Sapoetri, A., \& Pannindriya, T. (2019). Geliat Interaksi Sosial Dokter Masa Kini Melalui Media Sosial Instagram. Bricolage: Jurnal Magister Ilmu Komunikasi, 5(2), 121-140. https://journal.ubm.ac.id/index.php/bricolag e/article/view/1884 
Bricolage : Jurnal Magister IImu Komunikasi

Versi Online: http://journal.ubm.ac.id/

Vol.6 (No. 1) : 64 - 134 Th. 2020

Hasil Penelitian

p-ISSN: 2502-0935 e-ISSN: 2615-6423 